\title{
Analysis of dehumidification and humidity removal process of desiccant wheel ${ }^{\S}$
}

\section{Osman Kara', Ertaç Hürdoğan², Orhan Büyükalaca ${ }^{3}$}

\author{
1,2,3Energy System Engineering/ Osmaniye Korkut Ata University, Turkey
}

\begin{abstract}
Desiccant cooling technology is an environmentally attractive alternative to conventional mechanical air conditioning. A desiccant cooling system is a suitable way to improve indoor air quality due to its superior humidity control and it also provide as economical and cleaner for hot and humid regions. The most important component of the technology is the desiccant wheel which is used to remove the humidity of air. In this study, the analysis of dehumidification and humidity removal process of desiccant wheel were carried out using the performance data given by manufactures of the desiccant rotary wheel. Two parameters $\left(\mathrm{F}_{\mathrm{d}}, \mathrm{F}_{\mathrm{r}}\right)$ were defined for the analysis of the process. It was found that dehumidification and regeneration processes do not occur at constant wet bulb temperature. An equation for $\mathrm{F}_{\mathrm{d}}$ and $\mathrm{F}_{\mathrm{r}}$ which depends on the humidity ratio of outdoor air and regeneration temperature was composed.
\end{abstract}

Keywords: Air conditioning, Desiccant cooling, Dehumidification, Desiccant wheel,

\section{INTRODUCTION}

Desiccant cooling consists in dehumidifying the incoming air stream by forcing it through a desiccant material and then drying the air to the desired indoor temperature. To make the system working continually, water vapour adsorbed/absorbed must be driven out of the desiccant material (regeneration) so that it can be dried enough to adsorb water vapour in the next cycle. This is done by heating the material desiccant to its temperature of regeneration which is dependent upon the nature of the desiccant used. A desiccant cooling system, therefore, comprises principally three components, respectively, the regeneration heat source, the dehumidifier (desiccant material), and the cooling unit [1].

The purpose of a solid desiccant cycle is to reduce the moisture content of the ambient fresh air. A typical approach for using solid desiccants for dehumidifying air streams is to impregnate them into a light-weight honeycomb or corrugated matrix that is formed into a wheel. The wheel is usually divided into two sections. The process air flows through one section of the wheel to be dehumidified, while a reactivation airstream passes through the other section to regenerate the wheel. The desiccant wheel rotates slowly between the process and the regeneration airstreams in order to make the process continuous [2].

The solid desiccants are used in different technological arrangements. One of the typical arrangements consists of a slowly rotating wheel impregnated with a desiccant like a silica gel or a molecular sieve, in which a part of the wheel is intercepting the incoming air stream while the rest of it is being regenerated. For continuous operations, adsorption and regeneration must be performed periodically. Solid desiccants are compact, less subject to corrosion and carryover, hence in comparison with the other methods, desiccant wheels are more common [3]. Many researches carried out a lot of studies for design, modeling and optimization of solid desiccant cooling. Jia et al. [4] improved desiccant wheel adsorption efficiency about $50 \%$ by preparation of a new kind of hybrid desiccant (silica gel and lithium chloride). They investigated on the effect of a new adsorbent on desiccant cooling system and achieved 35\% efficiency increase to the silica gel [5].

Antonellis et al. investigated the use of a desiccant wheel for air humidification with a numerical and experimental approach. It is shown that the system can properly provide an air stream at satisfactory humidity ratio through an appropriate arrangement of the desiccant wheel. When the ratio process air flow rate to the regeneration air flow rate is greater than 1.3, the desired outlet humidity can be achieved. Besides the lower the outdoor air temperature, the higher the process air flow rate [6].

Two-stage desiccant wheel systems are an effective way to improve the dehumidification performance. Liu et al. compared the performances of a one-stage system and a two-stage system with identical heat transfer areas, with required

\footnotetext{
${ }^{*}$ Corresponding authour

Email: ehurdogan@osmaniye.edu.tr (E. Hürdoğan)

$\S$ This paper was presented at the IMSEC-2016
} 
heating source temperature. Compared to the one-stage system, the regeneration temperature of the two-stage system is lower [7].

In this study, the analysis of dehumidification and humidity removal process of desiccant wheel were carried out. In the analysis, the performance data given by manufactures of the desiccant rotary wheel was used. The effect of relevant parameters such as inlet air humidity, regeneration temperature, air mass flow rate, etc., on performance of desiccant wheel was discussed.

\section{MATERIAL AND METHOD}

The most important component of dehumidification air conditioning system is desiccant wheel. Some of the publications and introduction brochures related with the dehumidification regenerators point out that dehumidification and removal of humidity processes (regeneration, reactivation) realize approximately at constant enthalpy (approximately at constant wet bulb temperature) $[4,9]$.

Dehumidification and removal of humidity processes are represented with the curves $(A \rightarrow B)$ and $(C \rightarrow D)$ in Figure 1 . However, dehumidification and regeneration processes do not occur at constant wet bulb temperature according to the data given by the rotary desiccant wheel manufactures. Actual increase in dry bulb temperature during dehumidification $\left(A \rightarrow B^{\prime}\right)$ is higher than that of the constant wet bulb case $(A \rightarrow B)$. This is due to fact that a chemical thermal energy arises and the energy carried by the matrix of the wheel dehumidification regenerator from the regeneration air, which is hotter from the process air [8]. Because of this additional energy, dry bulb temperature further increases. The ratio of additional dry bulb temperature increase $\left(t_{B},-t_{B}\right)$ to total dry bulb temperature increase $\left(t_{B},-t_{A}\right)$ was defined as:

$$
F_{d}=\frac{t_{B}-t_{B}}{t_{B}-t_{A}}
$$

Similarly, dry bulb temperature decrease higher than constant wet bulb temperature case during regeneration $\left(C \rightarrow D^{\prime}\right)$, due to sensible heat transfer to the process air. The ratio of additional dry bulb temperature decrease $\left(t_{D},-t_{D}\right)$ to total dry bulb temperature decrease $\left(\mathrm{t}_{\mathrm{D}},-\mathrm{t}_{\mathrm{C}}\right)$ was also defined as:

$$
F_{r}=\frac{t_{D}-t_{D}}{t_{D}-t_{C}}
$$

It is important to determine the values of $\mathrm{F}_{\mathrm{d}}$ and $\mathrm{F}_{\mathrm{r}}$ accurately to able to analysis the desiccant cooling systems. In this study the performance data given by manufactures of the desiccant rotary wheel was used to calculate $\mathrm{F}_{\mathrm{d}}$ and $\mathrm{F}_{\mathrm{r}}$. Analysis of the data released that $\mathrm{F}_{\mathrm{d}}$ and $\mathrm{F}_{\mathrm{r}}$ are functions of dry bulb temperature and humidity ratio of the dehumidified (process) air and the regeneration air.

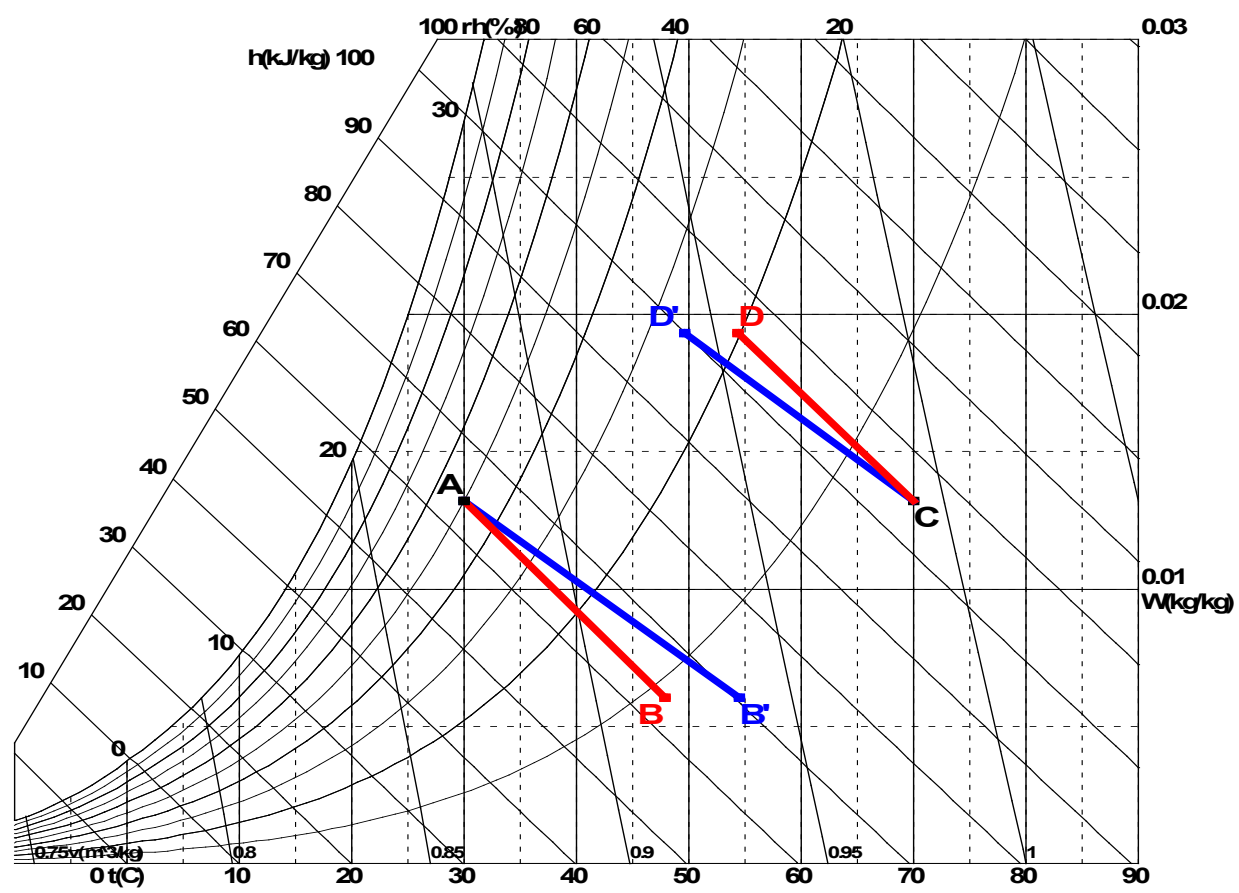

Figure 1. The process of dehumidification (A-B) and removal of humidity (C-D) 


\section{RESULTS ANS DISCUSSION}

In this study; the humidity ratio of the process air and the regeneration air are equal, since the same outdoor air was used as the process air and the regeneration air. Figure 2 shows the variation of $F_{d}$ values with the humidity ratio (W) of the outdoor air for a $70{ }^{\circ} \mathrm{C}$ regeneration air temperature $\left(\mathrm{T}_{\text {reg.temp. }}\right)$. In the figure, $\mathrm{F}_{\mathrm{d}}$ values are plotted for different outdoor air dry bulb temperatures varying between $25^{\circ} \mathrm{C}$ and $40^{\circ} \mathrm{C}$. As can be seen from the figure, $\mathrm{F}_{\mathrm{d}}$ decreases smoothly with increasing humidity ratio of outdoor air and dry bulb temperature of the outdoor air has no significant influence on $\mathrm{F}_{\mathrm{d}}$. Similar results were obtained for different regeneration air temperatures.

Figure 3 shows the variation of $\mathrm{F}_{\mathrm{r}}$ values with the humidity ratio of the outdoor air for a $70{ }^{\circ} \mathrm{C}$ regeneration air temperature at different outdoor air dry bulb temperatures. As can be seen from the figure, results similar to with $\mathrm{F}_{\mathrm{d}}$ were obtained for $\mathrm{F}_{\mathrm{r}}$.

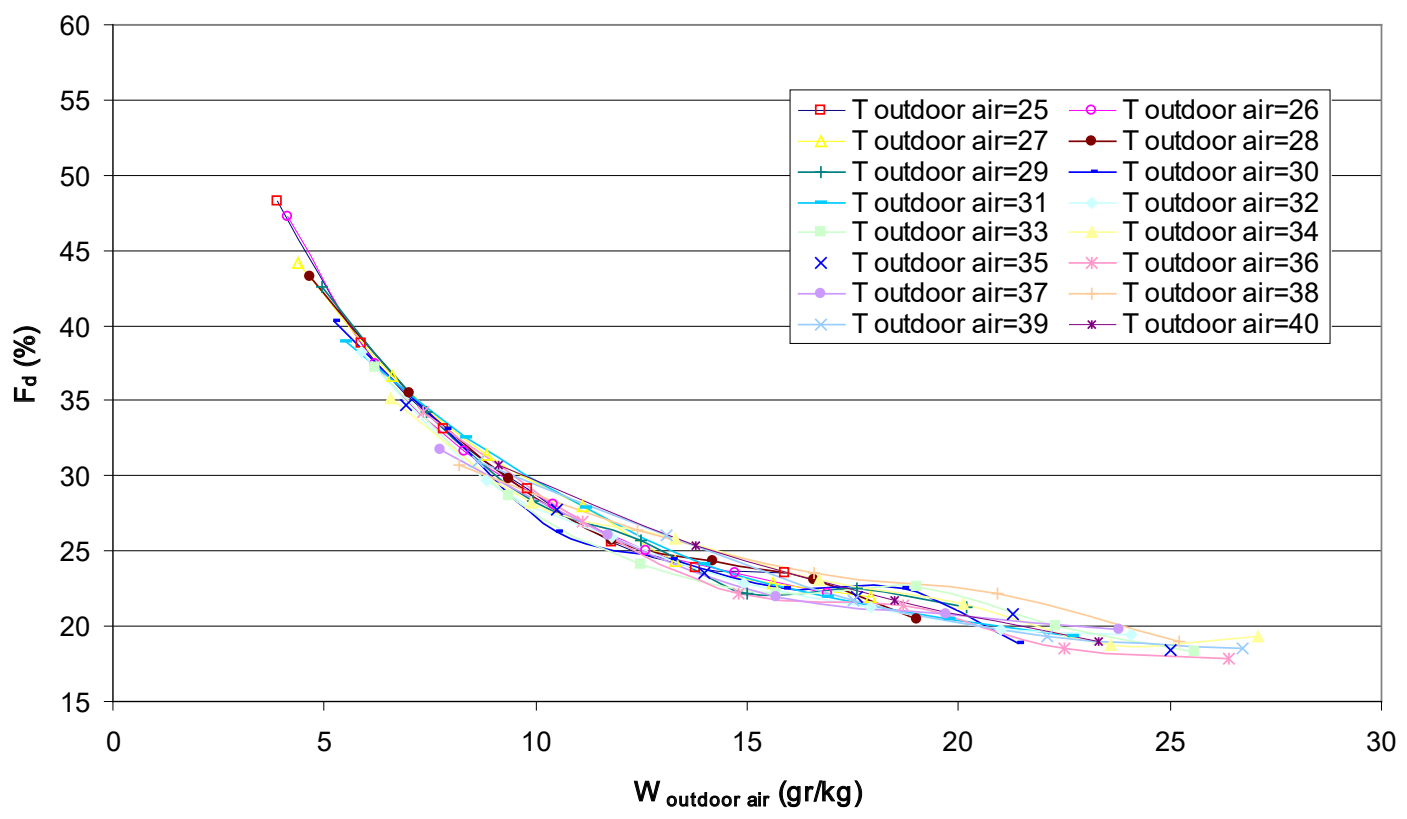

Figure 2. Variation of $\mathrm{F}_{\mathrm{d}}$ at $70{ }^{\circ} \mathrm{C}$ regeneration air temperature with humidity ratio of the outdoor air for different outdoor air temperatures

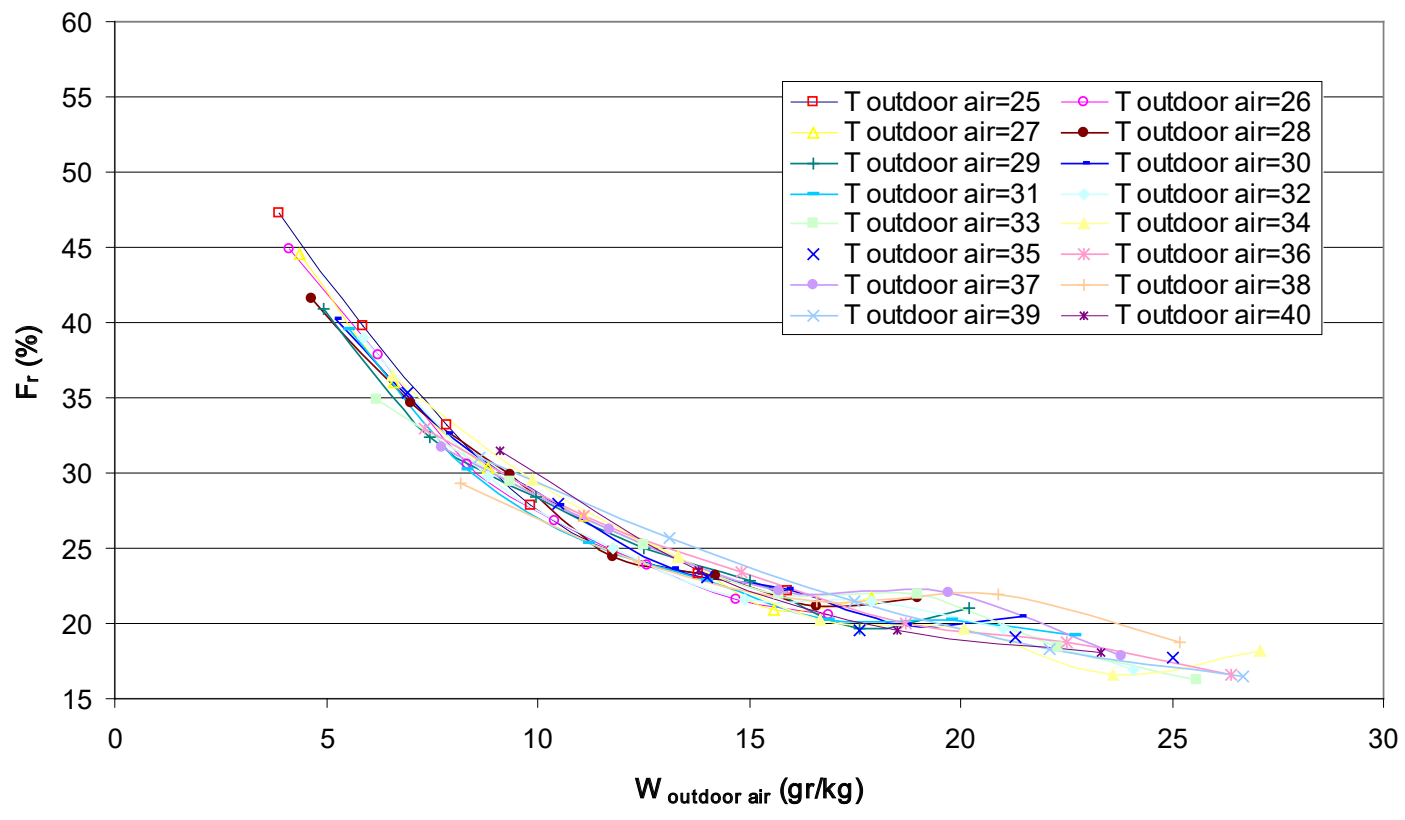

Figure 3. Variation of $\mathrm{F}_{\mathrm{r}}$ at $70^{\circ} \mathrm{C}$ regeneration air temperature with humidity ratio of the outdoor air for different outdoor air temperatures

Figure 4 shows values of $\mathrm{F}_{\mathrm{d}}$ and $\mathrm{F}_{\mathrm{r}}$, which were calculated for different regeneration air temperatures for dehumidification and humidity removal processes. As it can be seen from the Figure, $\mathrm{F}_{\mathrm{d}}$ and $\mathrm{F}_{\mathrm{r}}$ are almost the same for a given regenera- 
tion temperature. Therefore, the dehumidification and humidity removal data were handled together in order to obtain equations required for the system analysis. Figure 5 shows the values of $F_{d}$ and $F_{r}$, which were obtained at different regeneration air temperatures. The curves which were fitted (by using least square method) to the calculated data for each regeneration temperature were also shown in the figure.

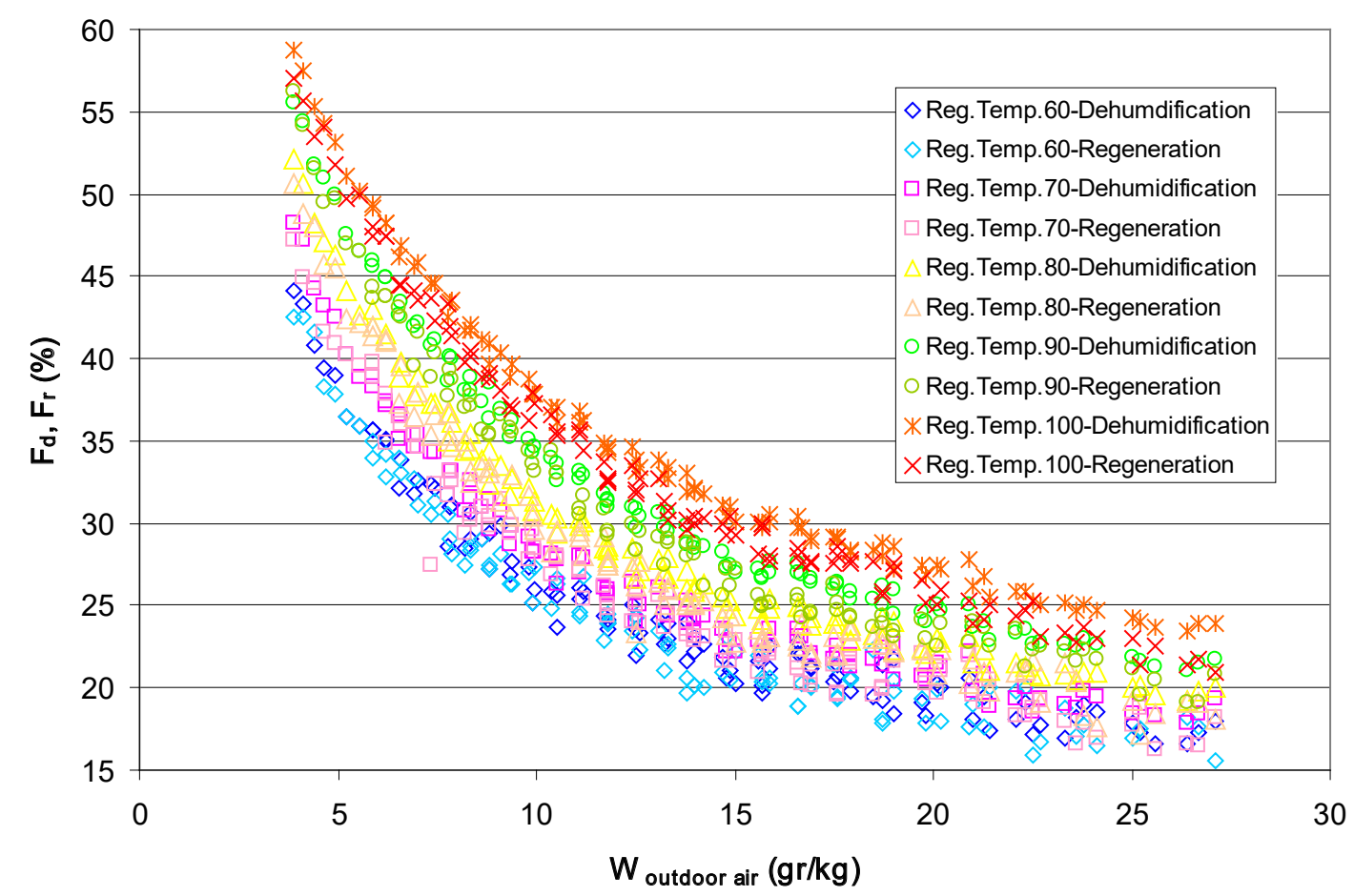

Figure 4. The values of $F_{d}$ and $F_{r}$ which were calculated at different regeneration air temperature for dehumidification and humidity removal processes

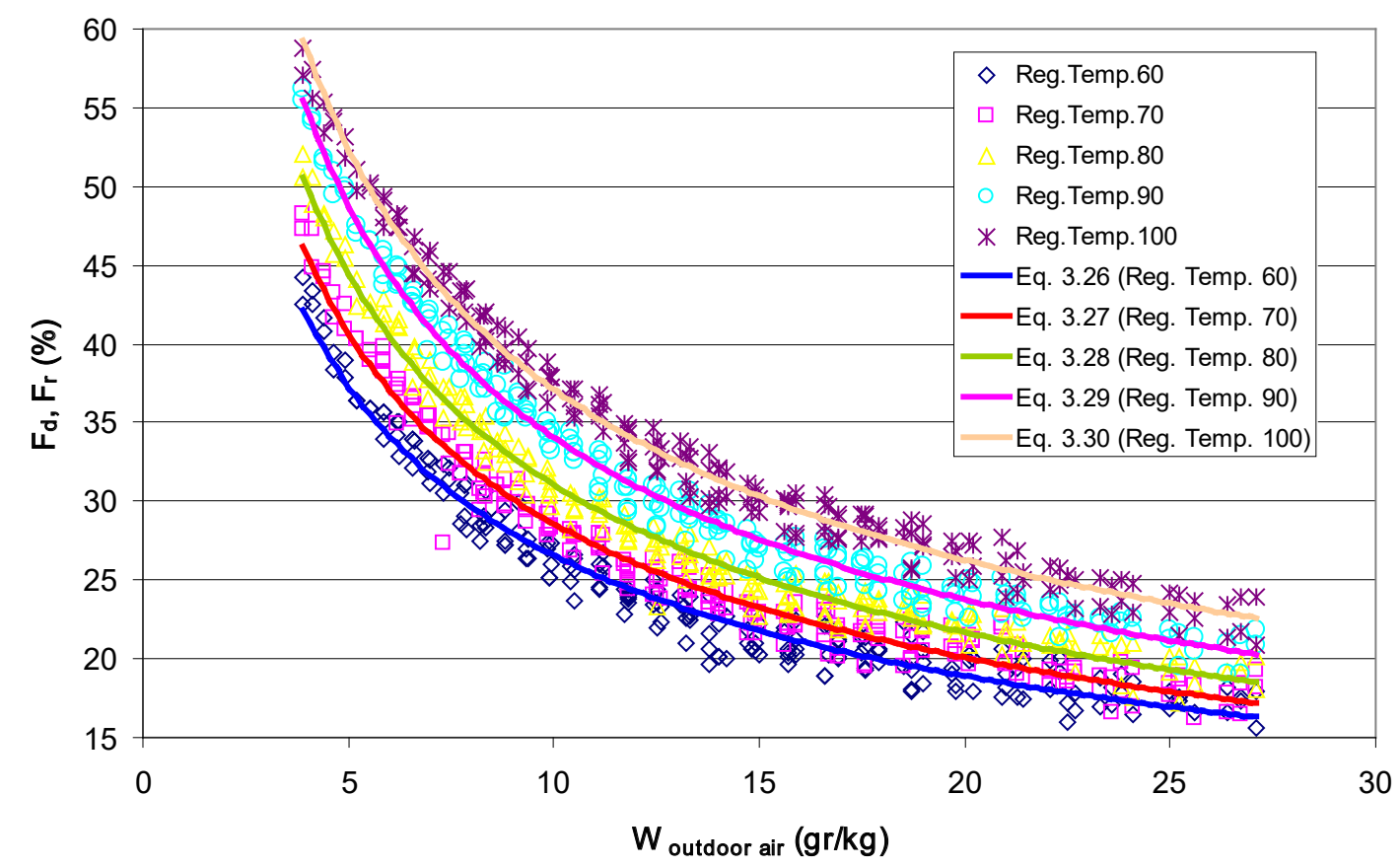

Figure 5. The values of $\mathrm{F}_{\mathrm{d}}$ and $\mathrm{F}_{\mathrm{r}}$, which were obtained at different regeneration air temperature, related with the humidity ratio of the outdoor air (Equations 3-7).

The equations of the curves which were fitted to the calculated data for each regeneration temperature were listed below:

$$
\mathrm{T}_{\text {reg.temp. }}=60^{\circ} \mathrm{C}: \quad \mathrm{F}_{\mathrm{d}}=\mathrm{F}_{\mathrm{r}}=82.136 \times \mathrm{W}^{-0.4901} \quad\left(\mathrm{R}^{2}=0.957\right)
$$




$$
\begin{aligned}
& \mathrm{T}_{\text {reg. temp. }}=70^{\circ} \mathrm{C}: \quad \mathrm{F}_{\mathrm{d}}=\mathrm{F}_{\mathrm{r}}=92.289 \times \mathrm{W}^{-0.509} \quad\left(\mathrm{R}^{2}=0.970\right) \\
& \mathrm{T}_{\text {reg. temp. }}=80^{\circ} \mathrm{C}: \quad \mathrm{F}_{\mathrm{d}}=\mathrm{F}_{\mathrm{r}}=102.45 \times \mathrm{W}^{-0.518} \quad\left(\mathrm{R}^{2}=0.977\right) \\
& \mathrm{T}_{\text {reg. temp. }}=90^{\circ} \mathrm{C}: \quad \mathrm{F}_{\mathrm{d}}=\mathrm{F}_{\mathrm{r}}=112.41 \times \mathrm{W}^{-0.5188} \quad\left(\mathrm{R}^{2}=0.983\right) \\
& \mathrm{T}_{\text {reg. temp. }}=100{ }^{\circ} \mathrm{C}: \quad \mathrm{F}_{\mathrm{d}}=\mathrm{F}_{\mathrm{r}}=116.80 \times \mathrm{W}^{-0.4979} \quad\left(\mathrm{R}^{2}=0.983\right)
\end{aligned}
$$

Use of only one equation that is valid for all regeneration temperatures would be easier than use of separate equations for each regeneration temperature. In the next step of the study, possibility of representing all the data with only one equation was investigated. As a result, Equation 8 that includes influence of both humidity ratio of outdoor air and regeneration temperature was obtained:

$$
\mathrm{F}_{\mathrm{d}}=\mathrm{F}_{\mathrm{r}}=5.18 \times \mathrm{W}^{-0.507} \times \mathrm{T}_{\text {reg. temp. }}^{0.652} \quad\left(\mathrm{R}^{2}=0.96\right)
$$

Figure 6 shows the comparison of the values obtained from the curve and the real data. As seen from the figure, the equation follows the data successfully.

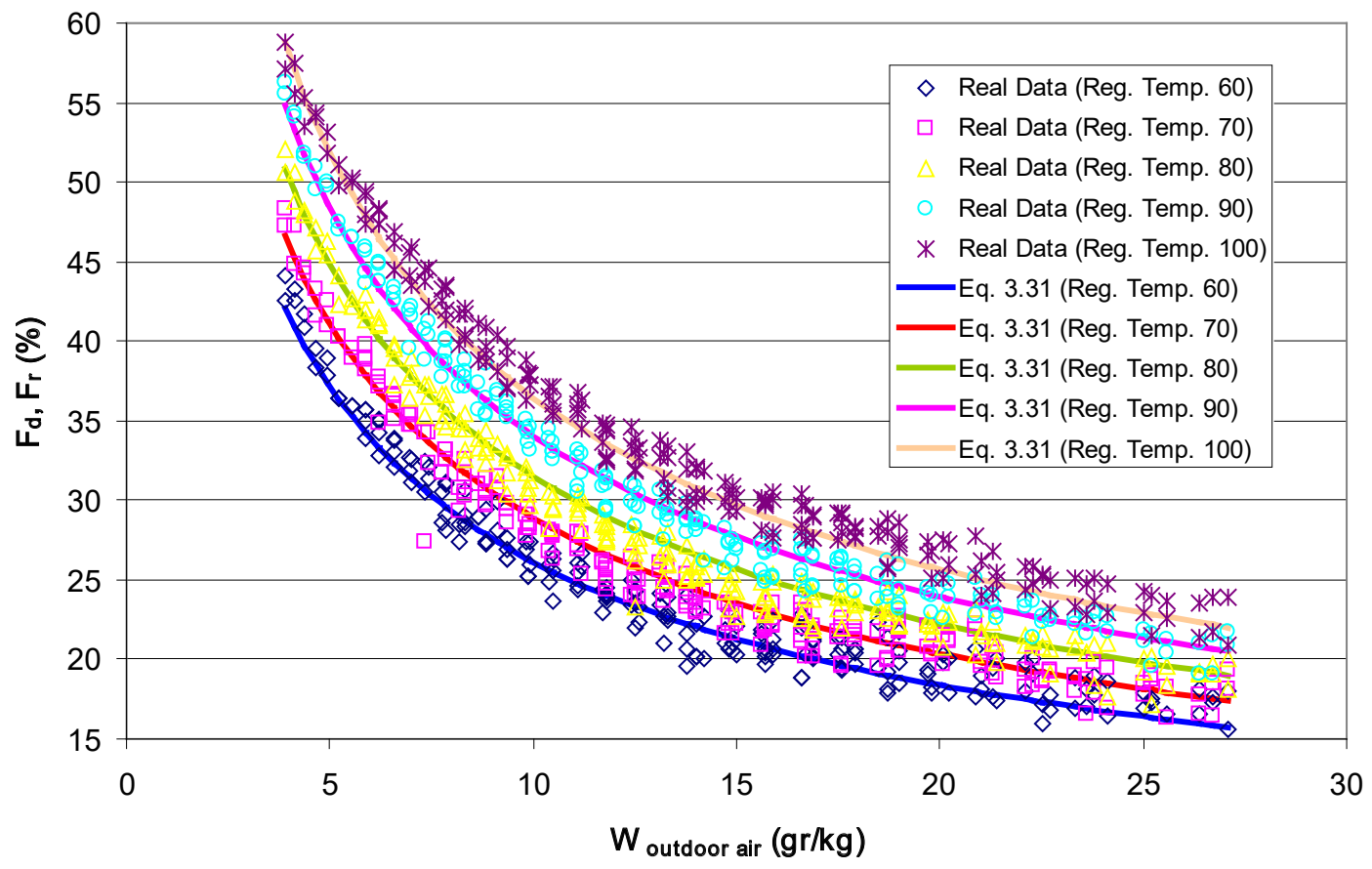

Figure 6. The values of $\mathrm{F}_{\mathrm{d}}$ and $\mathrm{F}_{\mathrm{r}}$ which were obtained at different regeneration air temperature related with the humidity ratio of the outdoor air (Equation 8).

\section{CONCLUSION}

In this study, the analysis of dehumidification and humidity removal process of desiccant wheel were carried out. The following main conclusions emerged from this study:

Dehumidification and regeneration processes do not occur at constant wet bulb temperature according to the data given by the rotary desiccant wheel manufactures.

Dry bulb temperature of the outdoor air has no significant influence on $\mathrm{F}_{\mathrm{d}}$ and $\mathrm{F}_{\mathrm{r}}$.

$\mathrm{F}_{\mathrm{d}}$ and $\mathrm{F}_{\mathrm{r}}$ are almost the same for a given regeneration temperature.

An equation for $\mathrm{F}_{\mathrm{d}}$ and $\mathrm{F}_{\mathrm{r}}$ which depends on the humidity ratio of outdoor air and regeneration temperature was composed. 


\section{REFERENCES}

[1] Daou, K., Wang, R., and Xia, Z. (2006). Desiccant cooling air conditioning: a review. Renewable and Sustainable Energy Reviews, vol. 10, no. 2, pp. 55-77.

[2] Al-Alili, A., Hwang, Y., and Radermacher, R. (2015). Performance of a desiccant wheel cycle utilizing new zeolite material: Experimental investigation. Energy, vol. 81, pp. 137-145. http://dx.doi.org/10.1016/j.energy.2014.11.084

[3] Ali Mandegari, M. and Pahlavanzadeh, H. (2009). Introduction of a new definition for effectiveness of desiccant wheels. Energy, vol. 34, no. 6, pp. 797-803. http://dx.doi.org/10.1016/j.energy.2009.03.001

[4] Jia, C.X., Dai, Y.J., Wu, J.Y., and Wang, R.Z. (2006). Experimental comparison of two honeycombed desiccant wheels fabricated with silica gel and composite desiccant material. Energy Conversion and Management, vol. 47, no. 15, pp. 2523-2534. http://dx.doi.org/10.1016/j.enconman.2005.10.034

[5] Jia, C.X., Dai, Y.J., Wu, J.Y., and Wang, R.Z. (2007). Use of compound desiccant to develop high performance desiccant cooling system. International Journal of Refrigeration, vol. 30, no. 2, pp. 345-353. http://dx.doi.org/10.1016/j.ijrefrig.2006.04.001

[6] De Antonellis, S., Intini, M., Joppolo, C.M., Molinaroli, L., and Romano, F. (2015). Desiccant wheels for air humidification: An experimental and numerical analysis. Energy Conversion and Management, vol. 106, pp. 355-364. http://dx.doi. org/10.1016/j.enconman.2015.09.034

[7] Liu, X.-H., Zhang, T., Zheng, Y.-W., and Tu, R. (2016). Performance investigation and exergy analysis of two-stage desiccant wheel systems. Renewable Energy, vol. 86, pp. 877-888. https://doi.org/10.1016/j.renene.2015.09.025

[8] ASHRAE (2004). Desiccant Dehumidification and Pressure Drying Equipment, American Society of Heating, Refrigeration and Air Conditioning Engineers, Vol.22, Atlanta.

[9] Kara O. (2009). Design of Air-Conditioning System with Dehumidification. Çukurova University Institute of Natural and Applied Sciences, Department of Mechanical Engineering. 